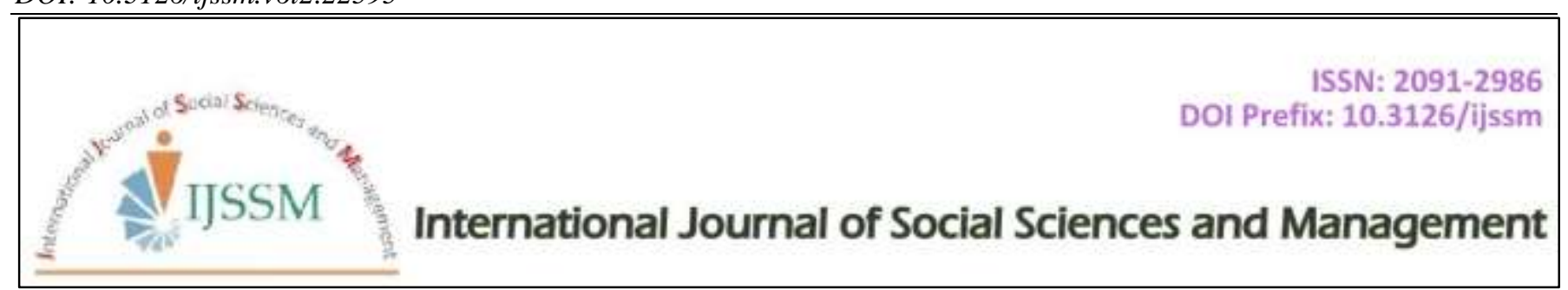

Research Article

\title{
Practices of Human Resource Management in Tribhuvan University
}

\author{
Milan Shrestha ${ }^{*}$
}

Kathmandu University School of Education, Lalitpur

\begin{abstract}
Human Resource Management (HRM) has been a crucial issue for Tribhuvan University (TU) due to the presence of a high number of students and teachers within the University Structure. The main purpose of this study was to explore the practices of the HRM in the TU. I adopted socio-constructivism as a research paradigm and narrative inquiry as the research design which is qualitative in nature. It used in-depth interview technique to collect information which was supported by literature review. TU conducts its overall human resource activities in coordination with executive bodies, campus chief, and line agencies like TUSC. The executive body is responsible for the entire HRM practices and other bodies have their own peculiar functions. For Instance, TUSC conducts the job design, job analysis, selection, recruitment, and performance appraisal process in the entire TU. HRM practices are familiar to the rules and regulations of TU and adopt them.
\end{abstract}

Keywords: Human resource management; Recruitment; Selection; Job analysis; Job design; Performance appraisal.

\section{Background of the Study}

Human Resources refer as the employee of the organization and Human Resource Management (HRM) is known as the design of management systems which ensures the human talent and uses it efficiently to garner organizational goals (Mathis et al., 2012; Bernardin, 2013). That's why, the human resources are an essential asset in the institution and it can be developed and its impact is maximized through the HRM. Dessler and Varkkey (2016) state that "HRM is the process of acquiring, training, appraising, and compensating employees, and of attending to their labor relations, health and safety, and fairness concern" (p. 4). Considering it, the HRM is the approach which deals with the planning, organizing, staffing and leading of human assets in the organization.
HRM includes the staffing, training and development, performance management and compensation and employee relations respectively. Staffing of HRM is also known as the HR procurement and it includes job analysis and design, HR planning, recruitment, selection, socialization and placement are the key factors (Decenzo \& Robbins, 1999; Durai, 2010). Among them, job analysis contributes to employees understanding their duties and responsibilities. Likewise, job design is associated with the skill variety, work identification, job significance, autonomy in job, and feedback (Norris \& Porter, 2012). In addition, Daniel and Malkar (2017) state that the recruitment refers to the process of searching and obtaining right people for the right position in an organization. Similarly, selection is the process where management chooses the best candidate from a pool of

\section{Cite this article as:}

M. Shrestha (2019) Int. J. Soc. Sc. Manage. Vol. 6, Issue-2: 40-46. DOI: 10.3126/ijssm.v6i2.22595

$1 *$ Corresponding author

Milan Shrestha,

Kathmandu University School of Education, Lalitpur

Email: milanshrestha313244@gmail.com

Peer reviewed under authority of IJSSM

(C) 2019 International Journal of Social Sciences and Management

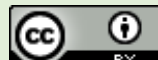

This is an open access article \& it is licensed under a Creative Commons Attribution 4.0 International License (https://creativecommons.org/licenses/by/4.0/)

Full text of this paper can be downloaded online at www.ijssm.org/ \&http://nepjol.info/index.php/IJSSM/issue/archive 
applicants who were deemed suitable for the job (Bratton \& Gold, 2003). Furthermore, the performance appraisal is associated with the evaluating guidelines of the employee performances in the organization. Overall, the job design, job analysis, recruitment, selection, and performance appraisal jointly form the HRM.

Tribhuvan University (TU), the pioneer public university of Nepal, was established in 1959 and is situated in Kirtipur, Kathmandu District (Adhikari, 2012). This university consists of a huge number of students as well as teachers. According to Ministry of Education (MOE, 2015), TU has 60 constituent campuses and it provided affiliation to 424 community and 639 private colleges respectively. MoE (2015) further reveals that the constituent colleges of TU consists 7966 Professors in 2015 and this figure excluded the number of part time teachers. This information claims that TU is the one of the largest University in Nepal and $11^{\text {th }}$ largest university in world (Tribhuvan University [TU], 2018). The entire TU is structured into 5 Institutes (e.g. Institute of Medicine, Institute of Science and Technology, Institute of Engineering, Institute of Agriculture and Animal Science, and Institute of Forestry) and 4 faculties (e.g. Faculty of Education, Faculty of Management, Faculty of Law, and Faculty of Humanities and Social Sciences). Furthermore, these all institutes and faculties are led by the Dean and Associated Deans. This university has run several research centers \{e.g. International Relations Center (CIR), Curriculum Development Center (CDC), Natural Science Museum, Office of controlling Examination (OCoE) \} and these centers were led by Coordinators and Directors. In addition, this University has formed a Tribhuvan University Service Commission (TUSC) for the recruitment of competent human resources in this institution. Furthermore, it conducts all HR activities with coordinating executive bodies as well as Human Resource Development and Welfare Council (HRDWC).

Human resource management (HRM) is essential to an organization's success but still it is neglected in the context of Nepal (Baniya, 2004). But recently, many organizations have adopted it as a single department but in most cases, they are still not fully autonomous to be able to make better decisions for the organization. This means the structure exist, but it cannot function properly. In the context of TU, large numbers of Human resources need proper incorporation. Subsequently, the practice of HRM in TU is in itself a complicated process in terms of performing the necessary task for the desired output.

These complicated practices of HRM have given the partial success in the organization instead of a complete one. Practices such as irregularity in examination; delay result publishing, regular class attaining and quality of teachers etc are seen as major drawbacks in the TU (Oho Nepal, 2016). In additional, the world ranking of TU is in decreasing stage while considering previous years (Consejo Superior de Investigaciones Cientificas [CSIC], 2018). It means that TU continuously loses its quality of output as well as reduces efficiency ensuring sub-standard performance. One of the vital causes of these short comings is lack of proper HRM practices in TU. Without improving on these aspects of HRM, TU will not able to address to solve its problems. There are several questions to be asked such as: What are the practices of HRM within Tribhuvan University? How the HRM activities were executed in the University? This study intends to explore the practices of HRM in TU and it also aims to identify the provision of job analysis, job design, recruitment, selection, and performance appraisal process in TU.

\section{Methodology of the Study}

Researcher adopted social constructivist view point as the research paradigm of this study where it sought the reality of the HRM practices in TU as its ontological assumptions. This ontological assumption leads to identify the knowledge about the practices of HRM in TU as its epistemological premises. This research adopted the methodological considerations as the Narrative inquiry method for describing and explaining the facts.

This study adopted qualitative research design and using narrative inquiry as the research methods and it also uses literature review to support facts which are derived from the interview techniques. The researcher collected qualitative data from the respondents and adopted purposive sampling as the sampling technique. Researcher determined purposively two senior administrative officers of the TUSC, two Campus chief of the constituent college and one Head of the Department (HOD) of TU as the respondents of this study. Then, I gave pseudonymous name for the entire respondents to maintain the ethical concerns (e.g. Afzal \& Tylor, 2016) in this study. Among these given names Mishra and Dangol were for senior administrative officers of TUSC, Thapa and Mandal represent for the campus chief of the constituent campus and Parajuli belongs to one of the Head of the Department of University Campus of TU. The characteristics of informants are in Table 1.

The researcher gathered required information from the selected respondent with the help of interview schedule. In this interview process researcher asked them various questions about the practices of different dimensions of HRM in TU. Researcher essentially conducted these interview based on the personalized set of questions. Then the collected information was coded and transcribed respectively for making them analyzable and interpretable. Eventually, the researcher analyzed and discussed themes; job analysis, job design, recruitment, selection, and performance appraisal which were moderately drawn from the gathered data. 
Table 1: Information of Participants

\begin{tabular}{llll}
\hline Participant & Gender & Caste and Ethnicity & Background \\
\hline Mishra & Female & Brahmin & TUSC \\
Dangol & Male & Newar & TUSC \\
Thapa & Male & Magar & Campus chief \\
Mandal & Male & Madhesi & Campus chief \\
Parajuli & Female & Brahmin & HOD \\
\hline
\end{tabular}

\section{Results and Discussions}

\section{Job Analysis}

Job analysis is the process of collecting prerequisite information related with various dimensions of a job and it ultimately includes its context, content and the job performer's required skill (DeNsi \& Griffin, 2008; Durai, 2010). It is an indispensable prerequisite for effective and efficient management of human resources in the organization. Job analysis is the base of HRM systems in each organization (Mukherjee, 2012; Caldwell, 2018). In fact, it specifies the duties concerned in a work and the factors that persuade the performance of the job (Siddique, 2004). In addition, Dessler and Varkkey (2016) mention "It produces the information for writing job descriptions and job specifications" (p. 85). The purpose of the job analysis is to providing the bases for doing rational decision as well as effective HR planning, conducting recruiting and selection process.

Dangol says "TUSC and executive bodies of TU played more magnificent role for doing job analysis in TU'. This job analysis guides the entire University for specifying the tasks. On the other hand, Mandal and Parajuli argues that Campus chief and Head of the department determines the job tasks and responsibilities in the constituent colleges and Departments of University campus which is one of the examples of job analysis. The Campus chief and Department head identify the tasks and its elements as the part of the job analysis. Then, they give these tasks to the teachers for executing the performance for getting better outcomes.

Overall, TUSC, Executive bodies, Campus chief and HOD plays significant role for doing job analysis and contributes for specifying the tasks within TU. Job analysis provides the information for preparing job descriptions and job specifications. This input is crucial for effective management of human resources in TU.

\section{Job Design}

Job design is defined as the organizing tasks, duties, responsibilities, and other ailments into a fruitful unit of work (Mathis et al., 2012). In another terms it is referred as splitting of the job for giving a tasks to employees in organization. Basically job design is the combination of the job content and work methodology which is adopted in the job (Durai, 2012). The well designed job ensures the effective performance and eventually contributes to the overall development of the organization. Durai (2012) further claims that "the basic aim of a job design is to clearly establish the role of each job and the job holder in the overall system of an organization" (p. 87).

Mishra reveals "TU classifies two types of job in organization which are teachers and administrative staffs". Considering it, TU identifies teachers in five levels which are Professor, Associate Professor, Assistance Professor, Lecturer and Teaching Assistance (TU, 1993). Among these posts teaching assistance is temporary in nature and it is appointed through the contract basis. In other hand Dangol stressed "TU classify other administrative staff as Administrator, Associate Administrator, Deputy Administrator and Assistance Administrator". Besides these jobs there is also provision of creating others job as well as sub job groups if the executive body identifies it essential (TU, 1994).

Academic council recognizes the essential competencies, duties and responsibilities for teachers but in case of administrative staffs these tasks are done through the executive bodies of TU (TU, 1994). Basically TU determine the eligible applicants as those individual who have acquired Master degree in second division for the post of teachers. Beyond this the Bachelor's degree holders are taken as eligible candidate for administrative staffs.

Mishra states "TUSC plays important role in designing job in $T U$ where it performs contributory role in job rotation, job enlargement and enrichment of the teachers". TU makes the provision that TUSC can give recommendation to executive bodies for changing the subjects of teachers from one particular subject to handling another subject (TU, 1993). On the other hand, TU further has made the provision that TUSC has full authority for conducting selection examination for placement of the vacant posts and also it can adopt one form as well as several forms of test for selecting best candidate. In addition, Mishra reveals "TUSC has further authority for constructing the curriculum to conduct selection exams of teachers as well 
as other human resources". Dangol further adds that TUSC has additional responsibilities for revising, updating and making the curriculum more effective for the selection purposes. TU has also given decision making power for deciding the candidate's qualifications either it is equivalent to meet the criteria given for the services or not when candidate's degree is from other universities (TU, 1993).

Mandal mentions: -

\begin{abstract}
"TUSC collects the job related information from the constituent colleges and create the post with job content and it basically belongs to job design. It further conducts the job analysis and identifies the duties and responsibilities for those created job. In addition, they also determine the job description with job specification of newly created post".
\end{abstract}

Finally, TUSC identifies the vacant post and recommends to the executive body of TU. In addition, executive body makes the decision based upon the recommendation of TUSC either created the post or not. Beyond it, the campus chief and HOD also are engaged in formulating Job design as the component of HRM in TU respectively in the constituent college and Department of University Campus. In this regard, Parajuli asserted that in some extent he organizes the tasks, duties and responsibilities in the Department which belongs to him. Furthermore, Mandal also agrees this claim and mentions that this practice contributes TU for getting better achievement.

Overall, the practice of job design in TU is basically related to the TUSC as well as its executive bodies. Despite it, Campus chief and HOD are also responsible in designing job in emergency situations. More specifically, TU designs two types of job; teaching and administrative job in organization. Primarily, the Academic councils identify the essential competencies, duties and responsibilities of employees in TU. In addition, TUSC plays contributory role for designing job and it further conducts job rotation, job enlargement and enrichment in TU as the practices of HRM.

\section{Recruitment}

Recruitment is the process of searching the suitable candidate for fulfilling the vacancies (Gusdorf, 2008) which happen in the organization. It can be referred as the certain process of generating a pool of competent candidates for a job in organization (Mathis et al., 2012). Thus, recruiting itself is a key component of enacting a HR plan. It is essential for addressing the unevenness in the workforce and it ensure that the organization has adequate human resources possessing the required qualities for best performing. Wilton (2011) divulges "Under strategies for organizational growth, diversification or development, or where organizations seek to replace leavers, this will require firms to recruit new members of staff or reposition existing employees" (p. 164).

International Labor Organization (ILO, 2012) sets the eligibility criteria for recruiting teachers in schools. It also makes certain criteria of eligibility for the recruitment process likes qualifications, certification, and proficiency in language related with instruction, citizenship and health status etc. This module has included the recruitment process and it varies according to the educational systems of the countries.

Considering it, Dangol expressed "When executive bodies of TU make the decision for creating the job then TUSC starts the process of recruiting by advertising the vacancy for required post in the government lead newspaper like Gorkhapatra daily and also in some social media". Mishra in this reference shared "TUSC mentions the required post as well as related information in the vacancy published advertisement. It further includes the job description including eligible qualifications and also makes the attraction to apply in the post for the eligible candidate". But in context of constituent campus, Parajuli and Mandal both states;

\footnotetext{
"In previous years, constituent Campuses as well as Departments used to recruit the contract basis teachers in campus but now TU does not allow it so we stop this recruitment practices in campus. However, we still announce the vacancy of part time teachers basically based on the necessity of the campus".
}

From this information, the researcher reveals that TUSC plays the vital role in entire recruitment process in TU as the HRM practices. Overall, the TUSC recommends the executive bodies for creating job. Then, executive bodies make the decision in the base of job design and its analysis. After this process, TUSC announces the vacancy for attracting best candidate in the job. In addition, the constituent Campuses and Departments take part in recruitment process while they needed some human resources in emergency condition.

\section{Selection}

Selection is the process of HRM which comes after the recruitment and ends at the placement process. Selection is the term which implies choosing few from those who applied (Saiyadain, 2009). Selection takes place after recruiting process where some few individuals will be selected from the entire applicants. Armstrong (2009) claims "Selection assesses the suitability of candidates by predicting their role successfully based upon the characteristics of applicants in terms of their competencies, experience, qualifications, education and training match the person specification" (p. 529). As well as, the selection process is choosing the best candidates who have 
prerequisite qualifications and it is required to full fill the vacant posts in an organization.

In context of TU, entire respondents agree that TUSC collects the application form and conducts written exams. Dangol asserts that the candidates who get success in the written exams are called for interview process. In addition, Mishra claims that TUSC further organizes the interview as well as background and certificate checking process. Both of the respondents from TUSC accept that those candidates who achieve high score process in this entire rigorous process are selected and ultimately they are appointed and places in the vacant posts.

Moreover, TU organizes the internal and open competition for fulfilling the vacant post (TUSC, 2013). In open competition, all eligible candidates can apply for the post either they are within the university or from outsider of the university. Moreover, TUSC (2013) determines some criteria for selecting suitable candidate for the post of teachers through the open competition namely educational qualification, research publication, teaching experience, training, written exams and interview respectively. For internal competition, TUSC determines some indicators like educational qualification, research and publication, teaching experience, performance appraisal and interview respectively. The remarkable thing is that all informants agree that "The minimum qualifications for being university teachers are set as the Master degree and they must score second division". Considering it, the educational requirement to be a university teacher is found insufficient in TU in comparison to the other renowned university. The renowned universities have provisioned that these candidates must have " $A$ " grade for being university teachers. Likewise, the participants further say that the TU also does not consider the total academic years of the candidate. In context of TU, some candidates have only 16 years academic year while accomplishing their Master degree. This information portrays that some few poor qualities candidate also get opportunities in the selection process as the university teachers which definitively degrade the quality of University. However, TUSC select these candidates and recommends to TU authority for recruiting them and finally $\mathrm{TU}$ appoints them in vacant posts (TUSC, 2013). Then, appointed teachers will spend 1-year probation period in their job. After this period, the employees who cross provisional period successfully are appointed as permanent employees in the organization.

In spite of this, Mandal and Parajuli both claim that TU has also provisioned appointment of the part-time faculty in contract basis if required. This can be done by respective Campus as well as Department can appoint contract basic teachers for maximum 2-years period and part time teachers for minimum 6 months to maximum 1-year duration with regards adopting the TU regulations (TU, 1993).
Overall, TUSC conducts the entire process from collecting applicants to the written exams as well as interview process and finally chooses the candidates and appoint them in post. In this process, firstly TU conducts open competition for all eligible candidates from outside the organization who deserve for the posts. The selection and recruitment of these new employees aims to accelerate the work performances and dynamisms in the organization. Secondly, TU also gives opportunity to its deserving and qualified employees to upgrade in higher post by conducting the internal competition. The internal competition increases the enthusiasm and promotes confidence among existing employees. Likewise, this process of selection motivates employees to upgrade their qualities and performances in organization. It also enhances job satisfaction among them. However, the TU allocates only few posts in this internal competition. So, the few employees only get opportunity to prospect in higher position via internal competition of TU. Likewise, the Campus chief and HOD also appoints temporary human resources in the constituent colleges.

\section{Performance Appraisal}

Performance appraisal is the procedure of identifying how well human resources do their jobs in relation to the well establish standard and communicate this information to them. It is used to assess a staff's performance and gives a platform for advising the expected performance about past, current, and future (Mathis et al., 2012). It is adopted as a tool for assessing performance of employees and it contributes for well performance management in TU. Likewise, it is widely used for administering salaries and wages, giving performance feedback and determining individual staff's strength and weakness. Basically organizations use performance appraisals in two approaches. Mathis et al. (2012) clarify that it provides a calculation of performance for deliberation in making pay or other administrative decisions about employees and another use is to focus on the development of individual performance in the future.

Mishra asserted that TUSC has developed the performance appraisal form for evaluating the candidates who appear in the internal competition as well as for the promotion process in the TU. TUSC makes the provision for taking performance appraisals of last one year before becoming candidates in the competition (TUSC, 2013). Dangol and Mishra accepted that-

\footnotetext{
"TUSC further makes the provision for evaluating the performance appraisal according to the annex 4 where it mentions that the performance appraisal of teachers as well as personnel is evaluated by the campus chief of the campus where they are engaged. As well as, Head of the Department assess the performance appraisal of those teachers who are engaged in the university campus and personnel
} 
engaged in research center are evaluated by the executive coordinator of those respective centers".

Dangol further adds that performance appraisal of campus chief and Head of the department are evaluated by the faculty Dean. Likewise, TUSC also makes the provision that Registrar evaluate the performance appraisal of the Dean while they (Dean) present themselves as a candidate in competition (TUSC, 2013). It further develops the provisions that Registrar had the responsibility for reviewing the performance appraisal of the teachers. However, if the Registrar evaluates the performance appraisal then reviewing responsibilities is on the Rector of the University. Mishra further asserted that-

\section{"If the performance appraisal of employee is acquired before the deadline then the score will be 4 to those candidates, otherwise, it will consider as 0. In addition, the score will also 0 when the candidates evaluate their performance appraisal from other unauthorized bodies."}

This information is analogous to the TUSC (2013) where it mentions the criteria of evaluating the employees of TU. This evaluation process is employed while promoting the employees in the organization. This practice of performance appraisal in TU is thus helpful for fair and transparent evaluation of employees in the organization. So, employees are found delegate and honest to their duties and work in organization. This honesty in job enhances the work productivity and performances of organization. As a result, the evaluation of performance appraisal promotes the employee performance in TU.

\section{Conclusion}

The executive bodies, TUSC, campus chief, and HOD practice the HRM in the TU. Among them, the executive body is more responsible for the entire HRM practices. Likewise, TUSC runs the job analysis, job design, recruitment, selection process, and performance appraisal in TU. That's why, the practices of HRM in TU contributes to design the job description, job specification, job enlargement, recruiting competent candidate, and evaluating the job performances of employees in the organization. These HRM practices promote the reformation process of organization, organizational change, increases work productivity, and work performances in TU.

\section{References}

Adhikari KP (2012) Human resource management in education $\left(\begin{array}{ll}l^{s t} & e d .\end{array}\right)$. Kathmandu: Oxford International Publication Pvt. Ltd.

Afzal B \& Taylor PC (2016) Uncovering management issues in Australian classrooms experienced by non-English speaking background teachers. Journal of Education and $\begin{array}{lllll}\text { Research 5(2) \& 6(1): 69-88. doi: } & \end{array}$ http://dx.doi.org/10.3126/jer.v5i2.15729
Armstrong M (2009) Armstrong's handbook of human resource management practice $\left(11^{\text {th }} \mathrm{ed}\right.$.). London: Kogan page limited.

Baniya LB (2004) Human resource development practice in Nepalese business organizations: A case study of manufacturing enterprises in Pokhara. The Journal of Nepalese Business Studies 1(1): 58-68.

Bernardin HJ (2013) Human resource management: An experiential approach. New York: McGraw Hill Companies.

Brattam J \& Gold J (2003) Human resource management ( $6^{\text {th }}$ ed.). Retrieved from http://www.macmillanine.com

Caldwell C (2018) Job analysis: The building block of human resource management. Retrieved from http://www.researchgate.net

Daniel LS \& Malkar VR (2017) Transformation of HR practices: Recruitment and selection. International Journal of Engineering Development and Research 5(2): 283-286.

Decenzo DA \& Robbins SP (1999) Human resource management ( $3^{\text {rd }} e d$.). New Delhhi: Pentice-Hall of India Pvt. Ltd.

DeNsi AS \& Griffin RW (2008) Human resource management ( $2^{\text {nd }}$ ed.). New Delhi: Biztantra.

Dessler G \& Varkkey B (2016) Human resource management $\left(14^{\text {th }} \mathrm{ed}\right.$.). Noida: Pearson Education, Inc.

Durai P (2010) Human resource management. Noida: Dorling kindersley (India) pvt. ltd.

Gusdorf ML (2008) Recruitment and selection: Hiring the right person. Alxandria society for Human Resource Management. Retrieved from http://www.shrm.org/hreducation

ILO (International Labor Organization) (2012) Handbook of good human resources practices in the teaching professional. Geneva: Author.

Mathis RL, Jackson JH \& Tripathy MR (2012) Human resource management: A south-Asia perspective $\left(13^{\text {th }}\right.$ ed.). Southwestern: Cenage learning.

Ministry of Education (2015) Nepali education in figures 2015: At-A-Glance. Kathmandu: Author.

Mukherjee J (2012) Designing human resource management systems: A learner's guide. Los Angeles: Sage Publications.

Norris SE \& Porter TH (2012) Job design. Wilney online library. Retrieved from https://doi.org/10.1002/9781118364741.ch53

Oho Nepal (2016) University in Nepal world ranking with drawback. Retrieved from http://www.ohonepal.com/university-in-nepal-worldranking

Saiyadain MS (2009) Human resource management ( $4^{\text {th }}$ ed.). New Delhi: Tata McGraw hill education Pvt. Ltd.

Siddique MC (2004) Job analysis: A strategic human resource management practice. The international Journal of 
Human Resource Management 15(1): 219-244. doi: 10.1080/0958519032000157438.

Tribhuvan University (1993) Tribhuvan bishwobidhalaya: Shikshak karmarchari sewa sambandi niyam 2050 [Tribhuvan University: Teacher personnel service regulation 2050]. Kathmandu: Author.

Tribhuvan University (1994) Tribhuvan bishwobidhalaya: Sangathan tatha saishik parshasan sambandi niyam 2050 [Tribhuvan University: Organization and educational administrative regulation 2050]. Kathmandu: Author.

Tribhuvan University (2018) Tri. bi. Uttakrista hajarma (TU in excellent one thousand). Retrieved from http://www.tribhuvan-university.edu.np
Tribhuvan University Service Commission (2013) Tribhuvan bishwobidhalaya siashiak niyukatika adhar, karya sampadhan mulkanyan thatha karya chamata aanka bivajan abam sifarish sambandi parkariya 2064 (2070 push 14 gatasama vayaka sansodhan sahit) [Tribhuvan University: Criteria for teacher appointment, process of performance appraisal, score division for performance proficiency and recommendation by policy 2064 (amendment until 2070 push 14)]. Kathmandu: Author.

Wilton N (2011) An introduction to: Human resource management. Los Angeles: Sage publications. 